\title{
Witness to Suffering: Mindfulness and Compassion Fatigue among Traumatic Bereavement Volunteers and Professionals
}

\author{
Kara Thieleman and Joanne Cacciatore
}

\begin{abstract}
This study used a survey to investigate the relationship between mindfulness and compassion fatigue and compassion satisfaction among 41 volunteers and professionals at an agency serving the traumatically bereaved. Compassion fatigue comprises two aspects: secondary traumatic stress and burnout. Because prior research suggests that compassion satisfaction may protect against compassion fatigue, the authors hypothesized that (a) mindfulness would be positively correlated with compassion satisfaction, (b) mindfulness would be inversely correlated with compassion fatigue, and (c) there would be differences between respondents with a personal history of traumatic bereavement and those with no such history. Correlation analyses supported the first two hypotheses; an independent means $t$ test did not provide evidence for the latter hypothesis, although the number of nontraumatically bereaved respondents was small. Overall, this sample showed surprisingly high levels of compassion satisfaction and low levels of compassion fatigue, even among respondents thought to be at higher risk of problems due to personal trauma. Implications of these findings are particularly relevant for social workers and other professionals employed in positions in which they encounter trauma and high emotional stress.
\end{abstract}

KEY WORDS: burnout; compassion fatigue; mindfulness; secondary traumatic stress; traumatic bereavement

$\Gamma$ here are recognized risks associated with working with traumatized individuals in a helping capacity. Although such work may be highly rewarding, professionals may experience negative cognitive, emotional, and behavioral effects that are often referred to as compassion fatigue (Adams, Boscarino, \& Figley, 2006; Bride, Radey, \& Figley, 2007). Compassion fatigue, defined in the literature as the reduced capacity for empathy toward clients resulting from the repeated exposure to their trauma (Adams et al., 2006), affects professionals and the clients they serve. Compassion fatigue encompasses the concepts of secondary (vicarious) trauma and burnout. Secondary trauma may take the form of symptoms included in the posttraumatic stress disorder diagnosis, including those related to avoidance, intrusion, and hyperarousal (Bride et al., 2007). Provider burnout, a concern in social work practice and other fields dealing with trauma and acute stress, also develops in response to intense interpersonal situations with high emotional and cognitive demands. However, it differs in that it comprises depersonalization, diminished accomplishment, and emotional exhaustion (Adams et al., 2006).
A history of personal traumatic experiences among helping professionals is thought to increase the likelihood of compassion fatigue, and an unsupportive workplace may increase burnout (Adams et al., 2006). However, other factors may be protective against compassion fatigue, including compassion satisfaction, which results from the positive experience of being able to help others. The presence of a supportive workplace may help reduce risk for some aspects of compassion fatigue, especially burnout (Adams et al., 2006; Collins \& Long, 2003). Although individuals in volunteer roles may spend fewer hours engaged with traumatized clients, research suggests that they are nevertheless at risk of secondary traumatic stress and burnout (Baird \& Jenkins, 2003). In one study of sexual assault and domestic violence staff, volunteers showed higher scores on some aspects of burnout than paid professionals, although there were no significant differences regarding overall burnout, secondary traumatic stress, or general distress (Baird \& Jenkins, 2003).

In recent decades, there has been a growing interest in mindfulness as a way to improve overall well-being of clients and helping professionals. 
Mindfulness has been defined as "the awareness that emerges through paying attention on purpose, in the present moment, and nonjudgmentally to the unfolding of experience moment by moment" (Kabat-Zinn, 2003, p. 145). Mindfulness practices, as used in the West, are largely adapted from Theravadan Buddhism, particularly from vipassana, or insight, meditation practices. These practices aim to decrease suffering and improve overall wellbeing through directing and sustaining attention in the present moment. Examples of specific practices include mindful eating exercises, a body scan that focuses attention on different areas of the body, yoga, walking meditation that emphasizes the awareness of bodily sensations, and sitting meditation that focuses on noticing thoughts, emotions, and sensations (Baer \& Krietemeyer, 2006).

Mindfulness-based practices have been used for a variety of purposes among medical and mental health care providers. These purposes include to reduce psychological distress (Rosenzweig, Reibel, Greeson, Brainard, \& Hojat, 2003) and increase empathy among medical students (Shapiro, Schwartz, \& Bonner, 1998), to decrease stress in nurses (Beddoe \& Murphy, 2004), and to decrease burnout symptoms and improve relaxation and life satisfaction in nurses and nurse aides (Mackenzie, Poulin, \& SeidmanCarlson, 2006). Such approaches have also been used to decrease stress, rumination, anxiety, and negative affect while increasing the self-compassion and positive affect of therapists in training (Shapiro, Brown, \& Biegel, 2007). In samples of health care professionals, including social workers, these approaches have been associated with decreased burnout and stress, as well as improved self-compassion, mental well-being, and quality of life (Goodman \& Schorling, 2012; Shapiro, Astin, Bishop, \& Cordova, 2005).

There is evidence that mindfulness meditation improves emotional adaptation and that attention regulation is a key component of this process (Desbordes et al., 2012). As a result, it is possible that higher levels of mindfulness, through increased emotional regulation, may protect against compassion fatigue and may also increase compassion satisfaction among those working with traumatized individuals and groups. This, in turn, may benefit both the professionals and the clients they serve. For instance, one randomized controlled trial found that clients of clinicians who practiced meditation had better outcomes than clients of clinicians who did not meditate (Grepmair et al., 2007).
Mindfulness may be a valuable tool for social workers, as both traditions emphasize the idea of decreasing suffering and improving lives (Turner, 2009). Mindfulness has also been identified as contributing to the development of empathy (Gerdes, Segal, Jackson, \& Mullins, 2011), which is essential for effective social work practice. Mindfulness can help clinicians build a strong therapeutic relationship by teaching them to be fully present, nonjudgmental, attuned, and accepting of both self and other (Turner, 2009). The ATTEND model, outlined below, is a mindfulness-based approach that may provide these benefits to social workers and the therapeutic relationship.

\section{CURRENT STUDY}

The current study draws on prior compassion fatigue and mindfulness research to further investigate the interaction between these constructs among professionals and volunteers at an agency that serves the traumatically bereaved. This agency uses a mindfulness-based model of care called the ATTEND model (Cacciatore \& Flint, 2012). Professionals and volunteers go through an intensive 30-hour training with this model. Supervision is centered around the model, and most trainees receive an additional four to eight hours a year in ongoing education. The elements of the ATTEND model are attunement, trust, therapeutic touch, egalitarianism, nuance, and death education; all these elements are practiced within a mindfulness framework based on provider self-compassion and care. Each element is briefly outlined below. For a detailed description of how this approach can be used in clinical practice, see Cacciatore and Flint (2012).

Attunement has been identified as one of the benefits of mindfulness. Attunement is practiced by demonstrating awareness and acceptance of unpleasant or painful emotions, building the capacity to tolerate such emotions in oneself, and modeling such tolerance for clients. This capacity helps the professional or volunteer establish trust with clients by remaining present, offering deep listening and validation, and expressing empathy. The element of therapeutic touch emphasizes the importance of appropriate, culturally sensitive touch with bereaved individuals after some degree of trust has been established. Mindfulness, through attention to the present moment and context, helps strengthen the ability to determine when 
such touch is warranted and when it might be counterproductive or unwanted. Egalitarianism is focused on reminding professionals and staff that they do not hold all of the answers to questions that clients face in the aftermath of a traumatic loss. Instead, they are encouraged to be mindful of each client's story and to tailor their approach to the client's unique needs, in accord with the client's preferences. Nuance is expressed through attentiveness to the unique circumstances of each individual, including their cultural background. Finally, death education is used to provide a foundation of knowledge regarding death, dying, and grief and to normalize a wide range of responses so that professionals and volunteers realize that there are many appropriate responses to loss. A commitment to mindfulness practice, such as sitting or walking meditation, is strongly encouraged for all professionals and volunteers at the agency.

Many of the professionals and volunteers at this agency have experienced traumatic loss personally, and thus they may be at risk for compassion fatigue as they see similar suffering in other individuals. It is hypothesized that mindfulness will be positively correlated with compassion satisfaction and negatively correlated with secondary traumatic stress and burnout. Furthermore, it is hypothesized that there will be a difference on all of these variables between respondents with a history of traumatic bereavement and those without such a history.

\section{METHOD}

\section{Participants}

Forty-one participants who volunteer or work at a local agency serving individuals who have experienced a traumatic death completed this survey. The mean age of the sample was 40.98 years (SD 9.21). Respondents were 92.7 percent female and 82.9 percent White, with 48.8 percent identifying as Christian, 26.8 percent indicating no religious preference, and the remainder of the sample indicating other faith traditions or an atheist/ agnostic orientation. The sample was predominantly partnered or married (90.2 percent), and 73.1 percent had earned a college degree. The mode for annual household income was between $\$ 50,001$ and $\$ 75,000$. This agency relies heavily on support from volunteers, most of whom are bereaved parents (82.9 percent in this sample). Among bereaved parents, the average time since
Table 1: Demographic Information $(N=41)$

\begin{tabular}{|c|c|c|c|c|}
\hline Characteristic & $n$ & $\%$ & $M$ & SD \\
\hline Age (in years) & 41 & 100 & 40.98 & 9.21 \\
\hline Bereaved parent & 34 & 82.9 & & \\
\hline Time since death of child & 34 & 82.9 & 6.41 & 3.65 \\
\hline Years in agency role & 41 & 100 & 3.44 & 2.36 \\
\hline Female & 38 & 92.7 & & \\
\hline \multicolumn{5}{|l|}{ Ethnicity } \\
\hline White & 34 & 82.9 & & \\
\hline Other & 7 & 17.1 & & \\
\hline \multicolumn{5}{|l|}{ Religion } \\
\hline Christian & 20 & 48.8 & & \\
\hline Other & 7 & 17.1 & & \\
\hline No preference & 11 & 26.8 & & \\
\hline Atheist/agnostic & 3 & 7.3 & & \\
\hline Partnered/married & 37 & 90.2 & & \\
\hline \multicolumn{5}{|l|}{ Education } \\
\hline High school only & 1 & 2.4 & & \\
\hline Some college courses & 8 & 19.5 & & \\
\hline College degree & 16 & 39 & & \\
\hline Some graduate courses & 2 & 4.9 & & \\
\hline Graduate or professional degree & 14 & 34.1 & & \\
\hline Employed outside the home & 38 & 92.7 & & \\
\hline \multicolumn{5}{|l|}{ Annual household income } \\
\hline$\$ 0-\$ 25,000$ & 2 & 4.9 & & \\
\hline$\$ 25,001-\$ 50,000$ & 6 & 14.6 & & \\
\hline$\$ 50,001-\$ 75,000$ & 11 & 26.8 & & \\
\hline$\$ 75,001-\$ 100,000$ & 7 & 17.1 & & \\
\hline$\$ 100,001-\$ 150,000$ & 8 & 19.5 & & \\
\hline$>\$ 150,001$ & 7 & 17.1 & & \\
\hline \multicolumn{5}{|l|}{ Role within agency } \\
\hline Support group facilitator & 15 & 36.6 & & \\
\hline Unspecified volunteer & 9 & 22 & & \\
\hline Mentor & 7 & 17.1 & & \\
\hline Online forums & 3 & 7.3 & & \\
\hline Counselor & 3 & 7.3 & & \\
\hline Other & 4 & 9.8 & & \\
\hline
\end{tabular}

the death of a child was 6.5 years $(S D=3.72)$, with a range of two to 15 years. Regarding the primary role within the agency, 36.6 percent were support group facilitators, some of whom were licensed clinicians in their communities, 17.1 percent were mentors, 7.3 percent were social workers or counselors providing grief counseling, and 39.1 percent served in other roles. Years of experience in this role ranged from one to seven years, with a mean of 3.44 years $(S D=2.36)$. Complete demographic information is provided in Table 1 .

\section{Procedures}

Potential participants were contacted via e-mail after agency board approval. Information about 
informed consent and a link to the survey were included. Continuing from the informed consent page to the survey was considered to indicate consent, as outlined to participants. The institutional review board at Arizona State University also approved the project. The survey was anonymous and contained questions regarding demographic information and personal experiences of child loss. It also used two validated instruments- the Mindful Attention Awareness Scale and the Professional Quality of Life Scale. The invitation to participate was sent to 76 professionals and volunteers. Fortysix took the survey, comprising a 61 percent response rate, although only 41 participants completed all items (54 percent response rate).

\section{Instruments}

Mindful Attention Awareness Scale (MAAS). The MAAS is a 15-item self-report scale designed by Brown and Ryan (2003) to assess mindful attention awareness, a key component of mindfulness. This component is thought to be an important aspect of emotional regulation (Desbordes et al., 2012) and is at the core of vipassana meditation practices. MAAS items (for example, "I find myself doing things without paying attention") are rated on a six-point Likert-type scale $(1=$ almost always; $6=$ almost never) regarding current experiences. A mean score is obtained by dividing the total score by the number of items, with higher scores indicating higher levels of this aspect of mindfulness. Mean scores can range from one to six. The developers report norms for community adults $(M=4.20, S D=0.69)$ and college students $(M=3.83, S D=0.70)$ in the preface to the instrument. Across samples, Cronbach's $\alpha$ for the MAAS ranged from .80 to .90 (Brown \& Ryan, 2003).

Professional Quality of Life Scale (PRoQOL). The PRoQOL is a 30 -item self-report measure developed by Stamm (2005) and adapted from the Compassion Fatigue Self-Test (Figley \& Stamm, 1996). It includes three subscales: compassion satisfaction (for example, "I like my work as a helper"), secondary traumatic stress (for example, "I can't recall important parts of my work with trauma victims"), and burnout (for example, "I feel worn out because of my work as a helper"). Items are scored on a five-point Likert-type scale $(1=$ never; $5=$ very often) within the timeframe of the past 30 days. The subscale scores are created by summing all the items in that subscale. Some items on the burnout subscale are reverse scored. The range of possible scores on each subscale is five to 50 , with higher scores reflecting higher levels of that component. Scores between 23 and 41 are considered average for all subscales. Scores of 22 and below on the compassion satisfaction subscale indicate low satisfaction with work, while scores of 42 and higher indicate high satisfaction. On the secondary traumatic stress and burnout subscales, scores of 42 and higher indicate potential problems in these areas and scores of 22 and below indicate low risk of problems in these areas (Stamm, 2009). A total score of all items is not derived. The developers report that Cronbach's $\alpha$ for the subscales are .88 for compassion satisfaction, .81 for secondary traumatic stress, and .75 for burnout (Stamm, 2009).

It may seem that the inclusion of volunteers in the current study would render the PRoQOL less applicable to this group, but a close evaluation of specific items on the scale reveals that many of the items are as relevant to volunteers as to paid professionals (see examples above). In addition, research suggests that volunteers who work with trauma survivors may share a similar risk of secondary traumatic stress and burnout compared to paid staff working with the same population (Baird \& Jenkins, 2003). Because volunteers are asked to make substantial time commitments to this agency, they may feel as invested as paid professionals. Many of the volunteers also have some clinical training.

\section{RESULTS}

The responses of the 41 participants who completed the survey were included in the analyses. Outliers were found in the MAAS and three PRoQOL subscales (four in MAAS, two in compassion satisfaction, one in secondary traumatic stress, and two in burnout) and were corrected to create a more normally distributed sample using the nearest score-plus-one method (Field, 2009). Reliability analyses were run for all scales: Cronbach's $\alpha$ was high for the MAAS (.91) and the compassion satisfaction subscale (.88) and was acceptable for the secondary traumatic stress subscale (.78), but it was low for the burnout subscale (.65).

\section{Descriptive Statistics}

The mean MAAS score for the sample was 4.25 $(S D=0.64)$. The mean scores for the PRoQOL subscales were $42.39(S D=4.80)$ for compassion satisfaction, $20.66(S D=4.00)$ for secondary 
traumatic stress, and $19.63(S D=4.93)$ for burnout. No participants scored in the low range for compassion satisfaction, and 71 percent $(n=29)$ scored in the high range. For secondary traumatic stress, 71 percent $(n=29)$ scored in the low range, and no participants scored in the high range that indicates problems. For burnout, no participants scored in the high range that indicates problems, and 76 percent scored in the low range. These results are summarized in Table 2.

\section{Correlation}

Correlation analyses were run to determine whether there was a correlation between MAAS score and scores on each of the PRoQOL subscales. Results revealed three significant relationships. There was a strong positive relationship between MAAS and compassion satisfaction $(r=.52, p=.001,95$ percent confidence interval (CI) $\left.[.25, .71], R^{2}=.27\right)$, a negative relationship of moderate strength between MAAS and secondary traumatic stress $(r=-.39, p=.01,95$ percent CI $\left.[-.62,-.09], R^{2}=.16\right)$, and a strong negative relationship between MAAS and burnout $(r=$ $-.54, p<.001,95$ percent CI $\left.[-.73,-.28], R^{2}=.30\right)$. These findings provide support for the hypothesized relationship between these variables, namely that mindfulness (specifically, attention awareness) is associated with greater compassion satisfaction scores and lower secondary traumatic stress and burnout scores.

\section{Independent Means $t$ Tests}

An independent means $t$ test was run to examine whether bereaved parents $(n=34)$, some of whom were licensed professionals, differed from nonbereaved parents $(n=7)$ on the four measures. None of the relationships between bereavement status and the four measures was significant. Two relationships — secondary traumatic stress and burnout - showed medium effect sizes. The study has a very small number of nonbereaved parents in the sample, so it is possible that a significant result would be obtained with a larger sample. In this case, the null hypothesis was retained, as there was no significant relationship between bereavement status and any of the four measures. Full results for the $t$ tests are provided in Table 3.

\section{DISCUSSION}

This study investigated the relationship between a core component of mindfulness, attention awareness, and compassion satisfaction and compassion fatigue among a group of professionals and volunteers who serve traumatically bereaved individuals. Social workers often find themselves in these types of high-stress or crisis roles within their communities, and research suggests they are at risk of experiencing burnout and other adverse psychological outcomes, especially if other personal risk factors or organizational conditions are

\begin{tabular}{lccccc}
\multicolumn{5}{c}{ Table 2: MAAS and PRoQOL Descriptive Statistics and Reliability (N= 41) } \\
\hline Instrument & $\mathbf{M}$ & SD & Minimum & Maximum & Cronbach's $\boldsymbol{\alpha}$ \\
\hline MAAS & 4.25 & 0.64 & 3.13 & 5.47 & 0.91 \\
PRoQOLs & & & & & \\
$\quad$ Compassion satisfaction & 42.39 & 4.80 & 33 & 50 & 0.88 \\
Secondary traumatic stress & 20.66 & 4.00 & 13 & 30 & 0.78 \\
$\quad$ Burnout & 19.63 & 4.93 & 11 & 31 & 0.65 \\
\hline
\end{tabular}

Note: MAAS = Mindful Attention Awareness Scale; ProQOL = Professional Quality of Life Scale.

Table 3: Independent Means $t$ Tests for MAAS and PRoQOL Subscales $(N=41)$

\begin{tabular}{|c|c|c|c|c|c|c|c|}
\hline \multirow[b]{2}{*}{ Instrument } & \multicolumn{2}{|c|}{ Bereaved } & \multirow[b]{2}{*}{ tdf } & \multirow[b]{2}{*}{$\boldsymbol{p}$} & \multirow[b]{2}{*}{$95 \% \mathrm{Cl}$} & \multirow[b]{2}{*}{ Cohen's d } & \\
\hline & $\begin{array}{c}\text { Yes } \\
(n=34) \\
M(S D)\end{array}$ & $\begin{array}{c}\text { No } \\
(n=7) \\
M(S D)\end{array}$ & & & & & \\
\hline MAAS & $4.25(0.65)$ & $4.26(0.65)$ & -0.03 & 39 & .98 & {$[-0.55,0.54]$} & -0.02 \\
\hline \multicolumn{8}{|l|}{ PRoQOL } \\
\hline Compassion satisfaction & $42.47(5.03)$ & $42.00(3.79)$ & 0.23 & 39 & .82 & {$[-3.61,4.55]$} & 0.11 \\
\hline Secondary traumatic stress & $20.21(4.04)$ & $22.86(3.24)$ & -1.63 & 39 & .11 & {$[-5.95,0.64]$} & -0.72 \\
\hline Burnout & $20.00(5.27)$ & $17.86(2.19)$ & 1.05 & 39 & .30 & {$[-1.99,6.28]$} & 0.53 \\
\hline
\end{tabular}


present (Adams et al., 2006; Lloyd, King, \& Chenoweth, 2002).

The reliability of the two instruments was found to be similar to what has been previously reported, with the exception of the burnout subscale of the PRoQOL. Though the burnout subscale has been noted to have lower reliability than the other two subscales that make up the PRoQOL (Stamm, 2009), the reliability of this scale was substantially lower than previously reported; thus, results involving this subscale should be interpreted with caution.

This sample showed slightly higher mindfulness scores (4.25) than the community average (4.20) reported by the developers of the MAAS. The majority of participants scored in the high range of the compassion satisfaction subscale of the PRoQOL, indicating high levels of satisfaction. The majority scored in the low range of the secondary traumatic stress and burnout subscales, indicating a low rate of symptoms in these areas. These findings suggest that respondents in this survey are not at high risk for compassion fatigue and instead have high levels of compassion satisfaction, thought to be protective against compassion fatigue.

This study found a significant positive relationship between mindfulness (attention awareness) and compassion satisfaction and significant inverse relationships between mindfulness and secondary traumatic stress and mindfulness and burnout in the correlation analyses. These results tentatively suggest that greater levels of mindfulness are associated with greater levels of compassion satisfaction, which is also thought to be protective against compassion fatigue, secondary traumatic stress, and burnout, although this latter subscale had low reliability. These findings are supported by past research showing that mindfulness is associated with overall wellbeing (Brown \& Ryan, 2003).

Contrary to prior research that suggests that individuals with a personal history of trauma may be at greater risk for compassion fatigue, this sample showed lower than average secondary traumatic stress and burnout scores and higher than average compassion satisfaction scores. In addition, no differences were observed between bereaved parents and nonbereaved parents in any of the four scales used in this study, though the number of nonbereaved participants was very small. These are very encouraging findings, particularly in light of prior research that showed intense and enduring psychological distress in bereaved parents compared to other bereaved groups (Leahy, 1992; Sanders, 1979).

These findings raise the possibility that elements of the agency's mindfulness-based ATTEND model may contribute to a decreased risk of secondary traumatic stress and increased levels of compassion satisfaction in this group. The unexpectedly high levels of compassion satisfaction and low levels of secondary traumatic stress and burnout found in this sample suggest that this particular agency may provide a model for supporting the well-being of individuals who work with clients after a traumatic loss. However, this study is not able to investigate this possibility directly, and more research is needed to investigate whether this, or other factors, may be responsible for the findings noted here. If further research supports the efficacy and benefits of this mindfulness-based model, it could be expanded and adapted for use in other high-intensity areas of social work, such as hospice settings or clinical work with trauma victims.

\section{Limitations}

This study has a number of limitations. It was conducted with a small, homogenous sample $(n=41)$ drawn from a single agency. This population has some unique features, such as the narrow group they serve (traumatically bereaved) and the finding that the majority (83 percent) has experienced a traumatic event in the form of child death. Due to the small number of nonbereaved parents, potential differences between these two groups could not be adequately explored. In addition, participants may have experienced other forms of trauma not captured by this survey. A similar study with a different helping population might yield different results. Even though responses were anonymous, respondents may have been motivated by social desirability bias. In addition, approximately 39 percent of potential participants did not take the survey, and some who participated (11 percent) did not complete all items. There may be important differences between these groups. Information regarding the amount of actual time participants spent with the traumatically bereaved was not obtained. There may be differences between those who work full-time with this population and those who spend fewer hours engaged with this group. The majority of respondents held other jobs in addition to their involvement with this agency, with only 7.3 
percent reporting not being employed outside the home. The inclusion of volunteers in this sample may have also influenced results. Despite the limitations, this study provides preliminary data regarding the relationship between mindfulness (attention awareness) and compassion fatigue and compassion satisfaction.

\section{Conclusion}

Prior research suggests that mindfulness is associated with greater overall well-being, but the relationship between mindfulness and compassion fatigue and satisfaction has not been adequately explored. This study builds on prior research regarding the benefits of mindfulness, going beyond what has previously been studied to examine a new population. Though this study found a significant positive relationship between mindfulness and compassion satisfaction and a significant negative relationship between mindfulness and compassion fatigue (secondary traumatic stress and burnout), more research is warranted. This study's most surprising findings were the high levels of compassion satisfaction and the low levels of compassion fatigue among volunteers and professionals at this agency. Further research is needed to test whether this finding is directly due to the mindfulness-based model used at the agency, as this cannot be determined by these data. Future research could use an experimental design to test whether and how mindfulness training impacts compassion fatigue among social work practitioners with and without a history of personal trauma. There is evidence that mindfulness can be an effective self-care strategy. Because mindfulness is teachable and has been shown to have a positive influence on emotional well-being, mindfulnessbased approaches could be adapted to benefit social workers as clinicians, interns, or volunteers working with individuals who have experienced trauma. $\mathbf{5 W}$

\section{REFERENCES}

Adams, R. E., Boscarino, J. A., \& Figley, C. R. (2006). Compassion fatigue and psychological distress among social workers: A validation study. American Journal of Orthopsychiatry, 76, 103-108. doi:10.1037/00029432.76.1.103

Baer, R. A., \& Krietemeyer, J. (2006). Overview of mindfulness- and acceptance-based treatment approaches. In R. A. Baer (Ed.), Mindfulness-based treatment approaches: Clinician's guide to evidence base and applications (pp. 3-27). San Diego: Elsevier.

Baird, S., \& Jenkins, S. R. (2003). Vicarious traumatization, secondary traumatic stress, and burnout in sexual assault and domestic violence agency staff. Violence and Victims, 18(1), 71-86.
Beddoe, A. E., \& Murphy, S. O. (2004). Does mindfulness decrease stress and foster empathy among nursing students? Journal of Nursing Education, 43, 305-312.

Bride, B. E., Radey, M., \& Figley, C. R. (2007). Measuring compassion fatigue. Clinical Social Work Journal, 35 , 155-163. doi:10.1007/s10615-007-0091-7

Brown, K. W., \& Ryan, R. M. (2003). The benefits of being present: Mindfulness and its role in psychological well-being. Journal of Personality and Social Psychology, 84, 822-848. doi:10.1037/0022-3514.84.4.822

Cacciatore, J., \& Flint, M. (2012). ATTEND: Toward a mindfulness-based bereavement care model. Death Studies, 36, 61-82. doi:10/1080/07481187.2011. 591275

Collins, S., \& Long, A. (2003). Too tired to care? The psychological effects of working with trauma. Journal of Psychiatric and Mental Health Nursing, 10(1), 17-27. doi:10.1046/j.1365-2850.2003.00526.x

Desbordes, G., Negi, L. T., Pace, T.W.W., Wallace, B. A., Raison, C. L., \& Schwartz, E. L. (2012). Effects of mindful-attention and compassion meditation training on amygdala response to emotional stimuli in an ordinary, non-meditative state. Frontiers in Human Neuroscience, 6, 1-15. doi:10.3389/fnhum.2012.00292

Field, A. (2009). Discovering statistics using SPSS (3rd ed). Thousand Oaks, CA: Sage Publications.

Figley, C. R., \& Stamm, B. H. (1996). Psychometric review of the Compassion Fatigue Self Test. In B. H. Stamm (Ed.), Measurement of stress, trauma, \& adaptation (pp. 127-128). Lutherville, MD: Sidran Press.

Gerdes, K. E., Segal, E. A., Jackson, K. F., \& Mullins, J. L. (2011). Teaching empathy: A framework rooted in social cognitive neuroscience and social justice. Journal of Social Work Education, 47(1), 109-131. doi:10.5175/ JSWE.2011.200900085

Goodman, M. J., \& Schorling, J. B. (2012). A mindfulness course decreases burnout and improves well-being among healthcare providers. International Journal of Psychiatry in Medicine, 43, 119-128. doi:10.2190/ PM.43.2.b

Grepmair, L., Mitterlehner, F., Loew, T., Bachler, E., Rother, W., \& Nickel, M. (2007). Promoting mindfulness in psychotherapists in training influences the treatment results of their patients: A randomized, double-blind, controlled study. Psychotherapy and Psychosomatics, 76, 332-338. doi:10.1159/000107560

Kabat-Zinn, J. (2003). Mindfulness-based interventions in context: Past, present, and future. Clinical Psychology: Science and Practice, 10(2), 144-156. doi:10.1093/ clipsy/bpg016

Leahy, J. (1992). A comparison of depression in women bereaved of a spouse, child, or a parent. Omega, 26, $207-217$

Lloyd, C., King, R., \& Chenoweth, L. (2002). Social work, stress and burnout: A review. Journal of Mental Health, 11, 255-265. doi:10.1080/09638230020023642

Mackenzie, C. S., Poulin, P. A., \& Seidman-Carlson, R. (2006). A brief mindfulness-based stress reduction intervention for nurses and nurse aides. Applied Nursing Research, 19(2), 105-109. doi:10.1016/j.apnr.2005. 08.002

Rosenzweig, S., Reibel, D. K., Greeson, J. M., Brainard, G. C., \& Hojat, M. (2003). Mindfulness-based stress reduction lowers psychological distress in medical students. Teaching and Learning in Medicine, 15(2), 88-92. doi:10.1207/S15328015TLM1502_03

Sanders, C. M. (1979). A comparison of adult bereavement in the death of a spouse, child, and parent. Omega, 10, 303-322. doi:10.2190/X565-HW49-CHR0-FYB4

Shapiro, S. L., Astin, J. A., Bishop, S. R., \& Cordova, M. (2005). Mindfulness-based stress reduction for health 
care professionals: Results from a randomized trial. International Journal of Stress Management, 12(2), 164-176. doi:10.1037/1072-5245.12.2.164

Shapiro, S. L., Brown, K. W., \& Biegel, G. M. (2007). Teaching self-care to caregivers: Effects of mindfulness-based stress reduction on the mental health of therapists in training. Training and Education in Professional Psychology, 1(2), 105-115. doi:10.1037/ 1931-3918.1.2.105

Shapiro, S. L., Schwartz, G. E., \& Bonner, G. (1998). Effects of mindfulness-based stress reduction on medical and premedical students. Journal of Behavioral Medicine, 21, 581-599. doi:10.1023/A:1018700829825

Stamm, B. H. (2005). The PRoQOL Manual: The professional quality of life scale: Compassion satisfaction, burnout $\&$ compassion fatigue/secondary trauma scales. Baltimore: Sidran Press.

Stamm, B. H. (2009). Professional quality of life: Compassion satisfaction and fatigue version 5 (PRoQOL). Retrieved from www.PRoQOL.org

Turner, K. (2009). Mindfulness: The present moment in clinical social work. Clinical Social Work Journal, 37 , 95-103.

Kara Thieleman, MSW, is a doctoral student, and Joanne Cacciatore, PhD, is assistant professor, School of Social Work, Arizona State University, Phoenix. Address correspondence to Kara Thieleman, School of Social Work, Arizona State University, 411 North Central Avenue, 822K, Phoenix, AZ 85004; e-mail:karajt@gmail.com.

Original manuscript received January 15, 2013

Final revision received March 9, 2013

Accepted March 24, 2013

Advance Access Publication January 1, 2014

\section{POINTS \& VIEWPOINTS}

If you would like to make a substantive re1 sponse to the premises, studies, and intellectual positions in an article you read in Social Work, this is your forum! This column seeks to stimulate dialogue that will help the profession respond to changing conditions. Send your manuscript (seven double-spaced pages or fewer) as a Word document through the online portal at http://swj.msubmit.net (initial, one-time registration is required).

\section{Customize the Power of Your} NASW Membership

\section{PRIVATE PRACTICE Specialty Practice Section}

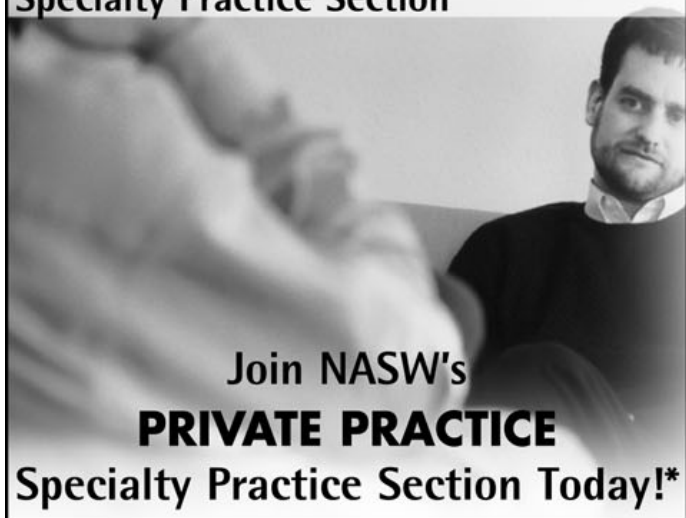

As a social worker in private practice, current information on trends and policy issues affecting practice and service delivery is a must. NASW's Private Practice Specialty Practice Section (SPS) links you with the key information, resources, and expertise you need to stay at the forefront of your practice specialty:

- Specialized newsletters

- Practice updates

- Opportunity for FREE CE credits by reading InterSections in Practice, the SPS annual bulletin

- Members-only Web-based products designed to enhance your professional development within the private practice community

\section{JOIN TODAY!}

Go to www.socialworkers.org/sections or call 202.408.8600 ext. 476 .

*You must be a current NASW member to join a Specialty Practice Section.

\section{(17) NASW. SPS}

National Association of Social Workers Specially Practice Sections

www.socialworkers.org/sections 202.408.8600 ext. 476 